\title{
Effects of EAF-Slag on alkali-activation of tungsten mining waste: mechanical properties
}

\author{
Naim Sedira ${ }^{1,}$, and João Castro-Gomes ${ }^{1}$ \\ ${ }^{1}$ Centre of Materials and Building Technologies (C-MADE/UBI), Department of Civil Engineering and Architecture, University of Beira \\ Interior (UBI), 6201-001 Covilhã, Portugal.
}

\begin{abstract}
The mechanical properties of alkali-activated binders based on blends of tungsten mining waste mud (TMWM) and electric arc furnace slag (EAF-S) were investigated. The synthesis of alkali-activated binders was conducted at $60^{\circ} \mathrm{C}$ for $24 \mathrm{~h}$ with different TMWM/EAF-Slag ratios (90:10, 80:20, 70:30, 60:40, and 50:50 vt.\%). Using sodium hydroxide (SH) and sodium silicate (SS) solutions as alkaline activators with ratio solid/liquid 4 by unit of volume, and the sodium silicate to $\mathrm{NaOH}$ (SS:SH) ratio of 2:1. The X-ray Diffraction (XRD), mercury intrusion porosimetry (MIP) were determined. The different percentages of the precursors and the alkaline activators were optimised to produce paste samples. The compressive strength of samples with 10 vt.\% EAF-Slag was close to $20.7 \mathrm{MPa}$ after 90 curing days. The mechanical properties were further increased up to $30 \mathrm{MPa}$ by increasing the percentage of EAF-Slag to $50 \mathrm{vt} \%$. This demonstrates a new potential for re-using waste material for various constructional applications.
\end{abstract}

\section{Introduction}

The use of slags in environmental applications were found to be eco-friendly as it does not possess any hazard to the health of people. These findings come from several leaching tests and numerous studies and have also been compared with the standards of the countries using steel slags [1]. The names and the main types of slags have been derived from the furnaces. In the process of the iron and steel making, two main types of slag are generated. For the process of ironmaking the type of slag generated is known as blast-furnace slag or (ironmaking slag); and in the process of steelmaking, the slag generated is known as steel-furnace slag. The steel furnace slag is divided into three groups [2]:

(a) Basic-Oxygen-Furnace (BOF) slag,

(b) Electric-Arc-Furnace (EAF) slag,

(c) Ladle slag.

According to the European association representing metallurgical slag producers and processors (EUROSLAG) the amount of steel slag produced in 2010 totals about 21.8 million tonnes. About $39 \%$ of this amount was generated as electric arc furnace slag. The main field of application for steel slag is to produce aggregates that are used for road construction. However, it is also known that around ( 1 to $10 \%$ ) is used in or other purposes such as fertilizer, hydraulic engineering and internal use for metallurgical purposes [3]. In alkaliactivation slags are one of the three most commonly used raw materials [4].

Recently, research studies and applications of alkaliactivated materials have concentrated on the use of nonconventional mineral waste such as mining waste, waste grounded glass, incineration products obtained from sewage sludge, and mineral wools. The chemical composition of novel precursors used in the production of alkali-activated materials is rich in alumina or silicates which are the main compounds in alkali-activated materials. Enormous quantities of waste resulting during the production process are disposed of in the open air causing a serious environmental impact. Thus, researchers investigate how to reuse this type of waste in the building and construction industry [5].

Many studies carried about use EAF-Slag in the alkaline activation. Khater [6] Studied the influence of electric arc furnace slag on characterisation of the produced geopolymer composites. The EAF-Slag-based alkaliactivated materials exhibit improved durability in high temperature environments in comparison with conventional cement-based materials, and the presence of $\mathrm{Ca}$ contained ingredients EAF-Slag as a result of alkali-activated products coexistence and $\mathrm{C}-\mathrm{S}-\mathrm{H}$ phase and maximal compressive strength. In other study the durability and the impact of electric arc furnace slag on geopolymer composites exposed to sulphate solution. The use of EAF-Slag in alkali-activation resulted in better stability against sulfate attack [7].

In Europe, the activities of mining and quarrying generate approximately $55 \%$ of total industrial wastes according to (Eurostat) [8]. Thus, the waste generated from mining and quarry industry accumulated in large deposits present a potential risk of environmental pollution and cause serious landscape impacts. The storage of these wastes directly on land may lead to various environmental issues [9]. Different mine tailings were used in various studies as precursors for alkali-

\footnotetext{
* Corresponding author: sedira.naim@ubi.pt
} 
activation. One of these precursors is tungsten mining waste mud (TMWM).

Tungsten tailing is waste generated from a tungsten mine. It can lead to environmental risk, like contamination of soil, pollution of water and air in the surrounding areas [10]. The processing industries of tungsten lead to possible adverse health effects for humans because tungsten and some of its compounds have low solubility [11]. According to Castro-Gomes et al. [9] the mineralogy of tailings from Panasqueira tungsten mining waste was found to be mainly quartz and muscovite. Pacheco-Torgal et al. [12] in their initial study obtained alkali-activated materials using tungsten mine mud waste (TMWM) mixed with minor quantities of calcium hydroxide, sodium hydroxide and waterglass solutions. Prior to mixing, the mud was subject to a thermal treatment at $950{ }^{\circ} \mathrm{C}$ for $2 \mathrm{~h}$. Alkali-activated concrete was obtained from a mixture of limestone aggregates (aggregate/binder ratio $=1.5$ ). In turn, the alkali-activated binder consisted of a mix of tungsten mine waste mud and $10 \%$ of $\mathrm{Ca}(\mathrm{OH})_{2}$ with an alkaline activator $(\mathrm{NaOH})$, having a concentration of $20 \mathrm{M}$. The $\mathrm{H}_{2} \mathrm{O} / \mathrm{Na}_{2} \mathrm{O}$ molar ratio was 10,8 . For this combination, they obtained an alkali-activated concrete compressive strength of $\mathrm{fc}_{(56)}=65.3 \mathrm{MPa}$ at 56 days curing. Recently, G. Kastiukas et al. [13] obtained a new alkali-activated binder where $20 \%$ of the tungsten mining waste was replaced by milled glass powder to increase the overall $\mathrm{SiO}_{2}$ content. The compressive strength of alkaliactivated tungsten mud waste and milled glass waste binder was $22 \mathrm{MPa}$ after 28 days curing.

In this study, the compressive strengths and microstructural of several alkali-activated TMWM and EAF-Slag mixtures have been carried out. The difference in the mechanical properties stems from the different microstructures. The final aim of this experimental study is to determine the optimum percentage of EAF-Slag to obtain a binder with the best mechanical performances.

\section{Experimental program}

\subsection{Materials}

The materials used in this work are Tungsten Mining Waste Mud (TMWM) and Electric Arc Furnace Slag (EAF-S). The material processing method of TMWM was as follows: first, collect the mud waste from landfill filling by mud waste (Panasquera). Then, putting the mud in the oven with a temperature of $60^{\circ} \mathrm{C}$ for $24 \mathrm{~h}$ to dries. After that, crashing the dried mud to get the TMWM powder with crashing machine. Finally, the particles size was sieved under $500 \mu \mathrm{m}$.

The material processing method of EAF-Slag was as follows: drying the granulated EAF-Slag in oven with a temperature of $60^{\circ} \mathrm{C}$, for $24 \mathrm{~h}$, then grind the slag using crashing machine to obtain EAF-Slag powder with particles size under $500 \mu \mathrm{m}$.

The chemical compositions of TMWM and EAFSlag were defined using (SEM-EDX). The main chemical compositions of TMWM are $\left(\mathrm{SiO}_{2} ; 46.7\right.$ wt.\%), $\left(\mathrm{Al}_{2} \mathrm{O}_{3} ; 17\right.$ wt.\%) and $\left(\mathrm{Fe}_{2} \mathrm{O}_{3} ; 15.5\right.$ wt.\%). The main chemical composition of EAF-Slag $(\mathrm{CaO} ; 33.3$ wt.\%), $\left(\mathrm{Fe}_{2} \mathrm{O}_{3} ; 30.5\right.$ wt.\%), $\left(\mathrm{SiO}_{2} ; 15\right.$ wt.\%) and $\left(\mathrm{Al}_{2} \mathrm{O}_{3}\right.$; 10.1 wt.\%) such as described in table 1 .

Table 1. Chemical Composition ( $\%$ mass) of raw materials.

\begin{tabular}{lll}
\hline Composition & \multicolumn{2}{l}{ Materials } \\
\cline { 2 - 3 } & EAF-Slag & TMWM \\
\hline $\mathrm{Al}_{2} \mathrm{O}_{3}$ & 10.08 & 17.05 \\
$\mathrm{SiO}_{2}$ & 15.00 & 46.67 \\
$\mathrm{TiO}_{2}$ & 0.82 & 0.6 \\
$\mathrm{SO}_{3}$ & 0.19 & 7.9 \\
$\mathrm{~K}_{2} \mathrm{O}$ & - & 4.9 \\
$\mathrm{CaO}$ & 33.29 & 0.69 \\
$\mathrm{Fe}_{2} \mathrm{O}_{3}$ & 30.48 & 15.47 \\
$\mathrm{MgO}$ & 4.54 & 4.83 \\
$\mathrm{Na}$ & 0.13 & 0.85 \\
$\mathrm{Mn}$ & 3.13 & - \\
$\mathrm{Cr}$ & 2.08 & - \\
$\mathrm{ZnO}$ & - & 1.09 \\
\hline
\end{tabular}

X-ray powder diffraction using "Rigaku model D-MAX III/C" to identify the patterns for the original materials studied is shown in Fig 1.

The X-ray spectra of the TMWM indicates the crystalline nature of the precursors and the present of muscovite and quartz which were identified by their characteristic: as follows: muscovite (Ref. PDF\#461409), quartz (Ref. PDF\#46-1045) and clinochlore (ref. PDF\#29-0701). Muscovite is a dioctahedral layered structure in which a sheet of octahedral Al ions is sandwiched between two sheets of linked $\mathrm{SiO}_{4}$ tetrahedral with a general formula $\mathrm{KAl}_{2}\left(\mathrm{Si}_{3} \mathrm{Al}\right) \mathrm{O}_{10}(\mathrm{OH})_{2}$ as shown in figure 1a [12].

The X-ray diffractogram of the EAF-Slag present very complex XRD spectra shows in figure 1b. Different mineral phases with distinct peaks of high intensities and some overlapping peaks of low intensities were detected. The slow cooling conditions of the EAF-Slag allow the formation of various crystalline phases [2]. The primary ones being: Magnetite (Ref. PDF\#08-0479), Calcite (Ref. PDF\#86-2339), Siderite (Ref. PDF\#83-1764), Gehlenite (Ref. PDF\#87-0968), Wustie (Ref. PDF\#060615) and Calcium Silicate (Ref. PDF\#20-0237). 
a) TMWM

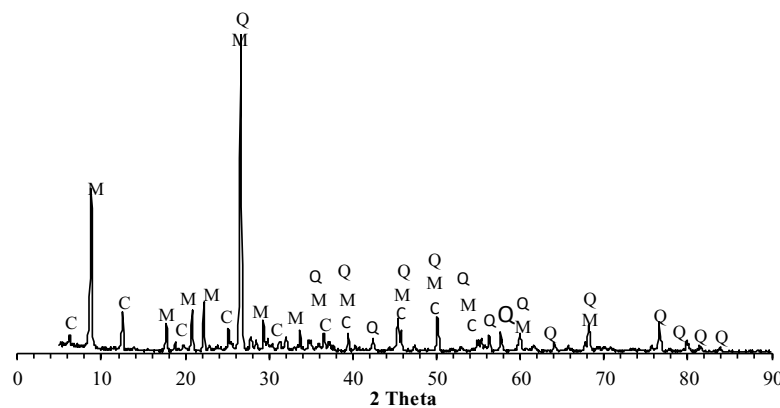

b) EAF-Slag

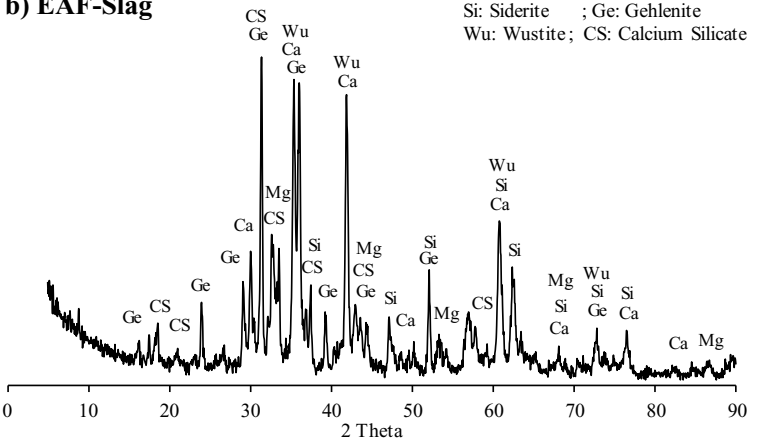

Figure 1: X-ray diffractograms of TMWM and RCBW, Phases identified are Quartz (Q), Muscovite (M), Clinochlore (C), Magnesite (Mg), Calcite (Ca), Siderite (Si), Gehlenite $(\mathrm{Ge})$, Wustie $(\mathrm{Wu})$ and Calcium Silicate (CS).

\subsection{Mix proportion of the binders}

In this investigation, the samples were mixtures of TMWM and EAF-Slag as precursors and sodium silicate, sodium hydroxide as alkaline activators with "Precursors / Activators" ratio of 4 . The ratio between the two raw materials, the $\mathrm{Na}_{2} \mathrm{O} / \mathrm{SiO}_{2}, \mathrm{SiO}_{2} / \mathrm{Al}_{2} \mathrm{O}_{3}$ ratios and Liquid/Solid ratio (L/S) are shown in Table 2.

The mixtures were activated with a combination of solutions: $(66.66 \%)$ of $10 \mathrm{M}$ Sodium Silicate (SS) " $\mathrm{Na}_{2} \mathrm{SiO}_{3}$ " L60, and (33.33\%) of $10 \mathrm{M}$ Sodium Hydroxide (SH) "NaOH". Sodium silicate solution $\left(\mathrm{Na}_{2} \mathrm{O}=8,6 \%, \mathrm{SiO}_{2}=27,8 \%, \mathrm{Al}_{2} \mathrm{O}_{3}=0.4 \%\right.$ and water $=$ $63,2 \%$ ) was obtained from Solvay SA, Portugal. And sodium hydroxide flakes of $98,6 \%$ purity was supplied by DOS SANTOS, LDA Portugal. Sodium hydroxide was dissolved using distilled water to provide 10 molarity alkaline solutions, (SH) solution was prepared one day prior to usage. Before beginning to prepare the mixtures, the activators are stirred together for 5 minutes with a mass ratio of $2: 1$.

Table 2. Mixture Compositions.

\begin{tabular}{|c|c|c|c|}
\hline $\begin{array}{l}\text { Samples } \\
\text { (vt.\%) }\end{array}$ & Binder Material & Variable & $\begin{array}{l}\text { Ratio } \\
\text { s }\end{array}$ \\
\hline \multirow{2}{*}{$\begin{array}{l}\text { EAF- } \\
\text { S01TM09 }\end{array}$} & \multirow{2}{*}{$\begin{array}{l}10 \% \text { EAF-S and } 90 \\
\% \text { TMWM }\end{array}$} & $\mathrm{Na}_{2} \mathrm{O} / \mathrm{SiO}_{2}$ & 0.05 \\
\hline & & $\mathrm{SiO}_{2} / \mathrm{Al}_{2} \mathrm{O}_{3}$ & 4.1 \\
\hline
\end{tabular}

\begin{tabular}{|c|c|c|c|}
\hline & & Liquid/Solid ratio (L/S) & 0.25 \\
\hline \multirow{3}{*}{$\begin{array}{l}\text { EAF- } \\
\text { S02TM08 }\end{array}$} & \multirow{3}{*}{$\begin{array}{l}20 \% \text { EAF-S and } 80 \\
\% \text { TMWM }\end{array}$} & $\mathrm{Na}_{2} \mathrm{O} / \mathrm{SiO}_{2}$ & 0.048 \\
\hline & & $\mathrm{SiO}_{2} / \mathrm{Al}_{2} \mathrm{O}_{3}$ & 4.3 \\
\hline & & Liquid/Solid ratio (L/S) & 0.25 \\
\hline \multirow{3}{*}{$\begin{array}{l}\text { EAF- } \\
\text { S03TM07 }\end{array}$} & \multirow{3}{*}{$\begin{array}{l}30 \% \text { EAF-S and } 70 \\
\% \text { TMWM }\end{array}$} & $\mathrm{Na}_{2} \mathrm{O} / \mathrm{SiO}_{2}$ & 0.047 \\
\hline & & $\mathrm{SiO}_{2} / \mathrm{Al}_{2} \mathrm{O}_{3}$ & 4.5 \\
\hline & & Liquid/Solid ratio (L/S) & 0.25 \\
\hline \multirow{3}{*}{$\begin{array}{l}\text { EAF- } \\
\text { S04TM06 }\end{array}$} & \multirow{3}{*}{$\begin{array}{l}40 \% \text { EAF-S and } 60 \\
\% \text { TMWM }\end{array}$} & $\mathrm{Na}_{2} \mathrm{O} / \mathrm{SiO}_{2}$ & 0.045 \\
\hline & & $\mathrm{SiO}_{2} / \mathrm{Al}_{2} \mathrm{O}_{3}$ & 4.74 \\
\hline & & Liquid/Solid ratio (L/S) & 0.25 \\
\hline \multirow{3}{*}{$\begin{array}{l}\text { EAF- } \\
\text { S05TM05 }\end{array}$} & \multirow{3}{*}{$\begin{array}{l}50 \% \text { EAF-S and } 50 \\
\% \text { TMWM }\end{array}$} & $\mathrm{Na}_{2} \mathrm{O} / \mathrm{SiO}_{2}$ & 0.044 \\
\hline & & $\mathrm{SiO}_{2} / \mathrm{Al}_{2} \mathrm{O}_{3}$ & 5.02 \\
\hline & & Liquid/Solid ratio (L/S) & 0.25 \\
\hline
\end{tabular}

The compressive strengths tests were performed on 3000 $\mathrm{KN}$ electro-hydraulic mechanical testing machine 'ADR Touch 3000 BS EN Compression Machine with Digital Readout and Self Centring Platens'. in accordance with ASTM C78.

The compressive strength data was obtained using cubic of dimensions of $25 \times 25 \times 25 \mathrm{~mm}$. These results obtained when added the EAF-Slag in increasing quantities to the TMWM as precursors, mixing with sodium silicate and sodium hydroxide as alkali activator solutions. After preparing the mixtures and molding the samples were placed in an oven at a temperature of 60 ${ }^{\circ} \mathrm{C}$ for 24 hours., after that cure the samples for 7, 14, 28 and 90 days in laboratory conditions.

\section{Results and discussion}

\subsection{Strength development}

The compressive strength results of EAF-S-TMWM alkali-activated binders (average of testing 5 specimens per each mixture) at the ages of 7, 14, 28 and 90 days are shown in Figure 2.

Generally, the higher dosages of EAF-Slag from 10 to $50 \mathrm{vt} \%$, the higher are compressive strengths. Besides, the compressive strengths of all the tested samples increased over the cure time. In the first 7 days of curing the compressive strengths present between $62.2 \%$ and $72.4 \%$ from the higher and final results at 90 days of curing. Significant development of compressive strengths in the first 7 days of cure were observed in the samples EAF-S02TM08 that gave 16.2 MPa which evolved to reach $22.4 \mathrm{MPa}$. That represents $72.4 \%$ from the final compressive strengths results of the same samples in 90 days. The positive development in 
compressive strengths were observed in terms of the added quantities of EAF-Slag. When the dosage of EAF$\mathrm{S}$ in the mixtures increase the compressive strengths increase. The samples EAF-S01TM09 represents the minimum value $17.9 \mathrm{MPa}$ and $20.8 \mathrm{MPa}$, in 28 and 90 days of cure respectively. While the samples EAFS05TM05 its compressive strengths were 23.5 MPa and $30.1 \mathrm{MPa}$ in 28 and 90 days of cure respectively. Its observed that the dosage of EAF-Slag have an influence on the compressive strength of the AABs. The compressive strengths growing up with $45 \%$ in the 90 days of cure, because of the augmentation in the amounts of EAF-Slag from $10 \mathrm{vt} \%$ to $50 \mathrm{vt} \%$ content in samples.

It also observed that the increase in the proportion of EAF-Slag corresponds to an increase in the $\mathrm{SiO}_{2} / \mathrm{Al}_{2} \mathrm{O}_{3}$ molar ratio, for the samples containing $10 \mathrm{vt}$ \% of EAFSlag the $\mathrm{SiO}_{2} / \mathrm{Al}_{2} \mathrm{O}_{3}$ molar ratio was 4.1 that increased with $23 \%$ to be 5.02 that correspond to the samples containing 50 vt.\% of EAF-Slag. This increase in $\mathrm{SiO}_{2} / \mathrm{Al}_{2} \mathrm{O}_{3}$ molar ratios results in a positive increase in the compressive strength of the tested EAF-S-TMWMbased alkali-activated binder specimens. The gels are responsible for the mechanical development of these materials. With the curing time, a higher amount of gels was formed and higher mechanical strengths were obtained [14]. Another feature was that the mixtures containing higher ratios of EAF-Slag generated better performance, so their chemical characteristics and especially their content (ratio) in (Cao) had an influence on binder strengths at any age. With high hydration modulus of EAF-Slag and most specifically its role in supplying soluble $\mathrm{Ca}^{2+}$ ions, forming additional $\mathrm{CSH}$ phases in addition to N-A-S-H as well as N-(C)-A-S-H leads extra strengthening of the matrix structure [15]. Which has a positive effect on enhancement in the mechanical properties of the resulting structure.

A higher dosage of EAF-S (50 vt.\%) involved higher mechanical strengths, 23.5 and $30.1 \mathrm{MPa}$ at 28 and 90 days for EAF-S05TM05 binder.

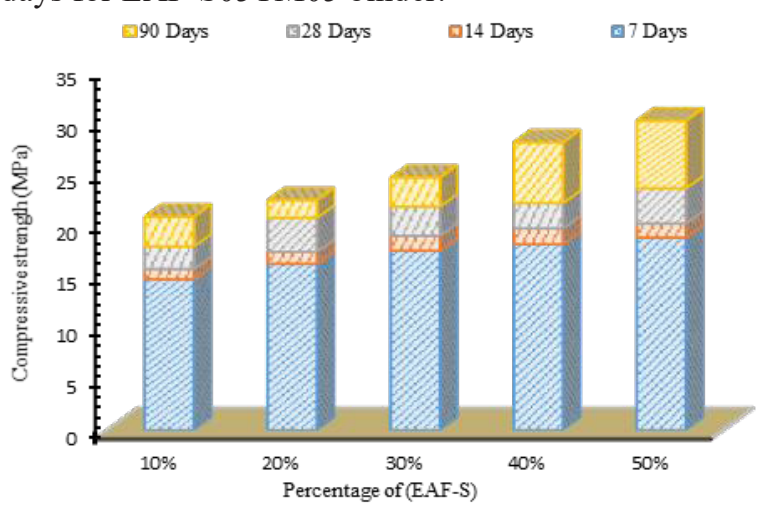

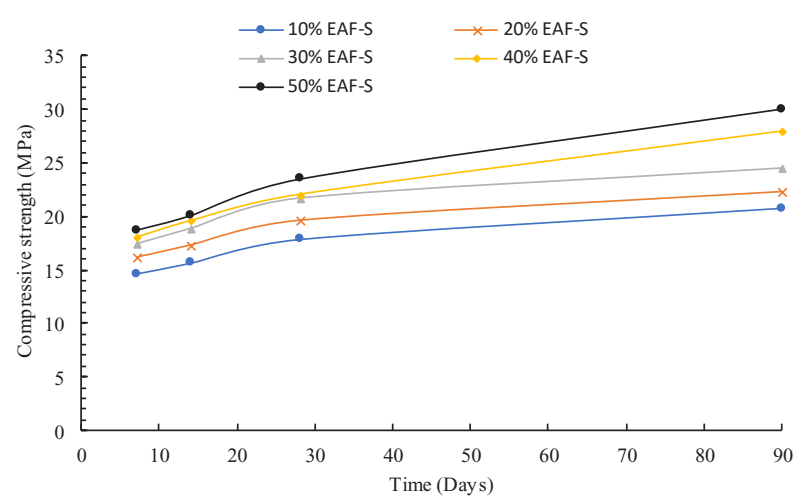

Fig. 2. Development in compressive strength of the AABs paste specimens contains different amounts of EAF-S in different cured days.

\subsection{Mercury Intrusion Porosimetry}

Mercury intrusion porosimetry (MIP), which is a wellestablished technique to investigate the pore structure of porous materials, the shrinkages and strengths of paste and mortar are associated with the porosity and pore size distribution of the samples [16]. Mercury intrusion porosimetry was adopted to study the pore structure of EAF-S-TMWM-based alkali-activated binders.

In this work, five samples of alkali-activated material (EAF-S01TM09, EAF-S02TM08, EAF-S03TM07, EAFS04TM06 and EAF-S05TM05) were tested by Microporometrics AutoPore IV 9500 V1.07. The data obtained by recording the volume of mercury that penetrates the porous specimen as a function of pressure. A minimum pore diameter of $0.005 \mu \mathrm{m}$ can be evaluated using MIP. Total volume of mercury intruded (which is the total porosity) and critical pore diameter (which is the peak in the differential volume intruded curve) can be obtained from MIP. The average pore diameter is calculated from the total pore volume and the pore surface areas [17]. The mercury intrusion porosimetry (MIP) results of the alkali-activated binders are shown (Fig. 3, Table. 3), the data were collected which were used to obtain the porosity and the average pore diameter, and the pore size distribution integral curve and the pore size distribution differential curve were also plotted.

The results show that porosities of the samples were different and changed with the change in the amounts of EAF-Slag added to the mixtures, the porosity measured varied from approximately $46.5 \%$ for the EAFS01TM09 paste cured for 90 days to $20.4 \%$ for the EAFS05TM05 paste cured for 90 days (Fig. 3a, Table. 3).

However, the increase of EAF-Slag amounts in the blended decrease the porosities in the different tested sample which resulting in increased densities. The high densities were beneficial to mechanical properties and durability of alkali-activated binder. Comparing to sample EAF-S01TM09, after adding (50 vt.\%) of EAF$\mathrm{S}$, the porosity and the average pore diameter of binders decreased by $56.2 \%$ and $27.1 \%$, respectively.

Fig 3b. shown a presence of a sharply defined intrusion peak in the differential curve indicates the 
intrusion of mercury throughout the specimen through a pore network connected to the specimen surface. It appears, that the initial intrusion peak observed here corresponds to the minimum throat dimension of an interconnected capillary network. The hydration reaction of $\mathrm{CaO}$ and silica, in addition to alkali-activation products expand into the pore space, it is logical that the size of connecting pores would diminish with the increase of EAF-Slag dosage in the mixtures. This corresponds to the experimentally observed movement of the initial peak to smaller pore widths [18]. Welldefined threshold pore widths were evident from approximately $2.1 \mu \mathrm{m}$ to $2.5 \mu \mathrm{m}$. The pore width corresponding to the highest rate of mercury intrusion per change in pressure is known as the 'threshold', 'critical' or 'percolation' pore width [19]. However, it may provide a better indicator of material durability as it has an important influence on the permeability and diffusion characteristics of the cement paste [20]. It seen that the increase in EAF-Slag dosages resulted a lower total porosity and medium values of threshold pore width for the EAF-S-TMWM-based alkali activated binder.

The average pore diameter for the sample with dosage (10 vt.\%) EAF-Slag was $118 \mathrm{~nm}$ decreased to $86 \mathrm{~nm}$ for the sample with (50 vt.\%) EAF-Slag.

The decrease in the total porosity and the pore width and the average pore diameter because the samples are exposed to the atmosphere in the days of cure, the $\mathrm{Ca}(\mathrm{OH})_{2}$ may react with $\mathrm{CO}_{2}$. The precipitator of this atmospheric carbonation, $\mathrm{CaCO}_{3}$, may precipitate in the pores of the sample thus reducing the total porosity and leading to higher compressive strength over the curing age.
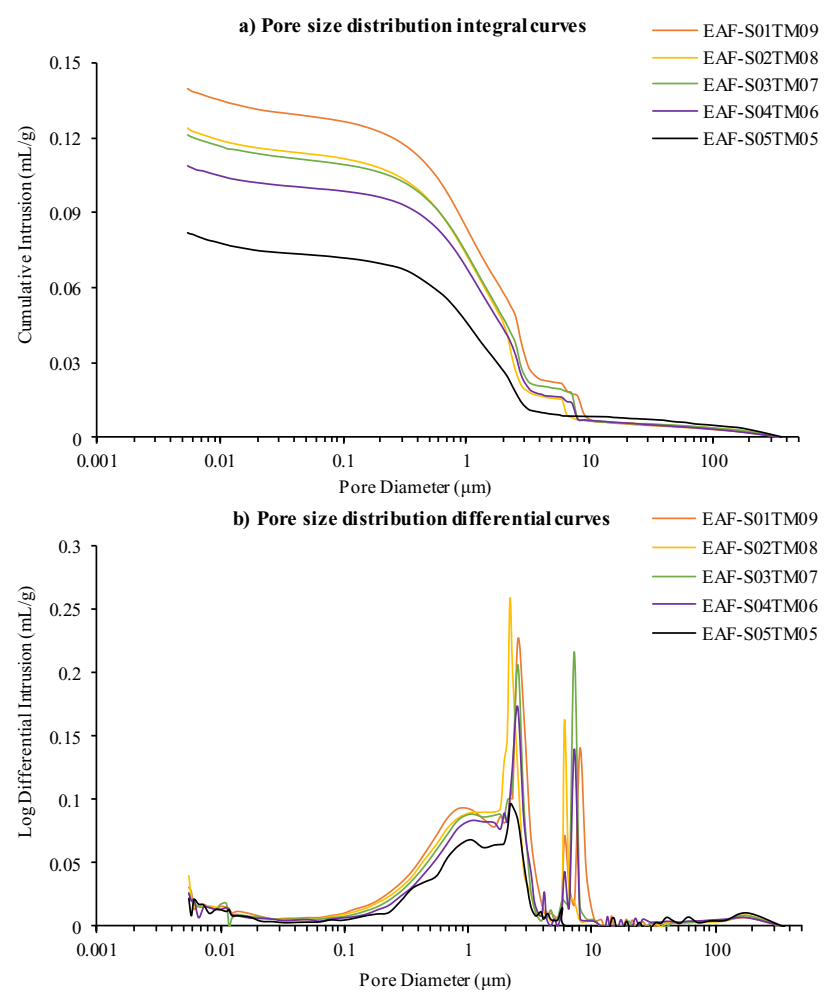

Fig. 3. Pore size distribution curves of EAF-S-TMWMbased alkali-activated binders.
Table 3. Mercury intrusion porosimetry parameters of the EAF-S-TMWM-based alkali-activated binders in 90 days.

\begin{tabular}{|c|c|c|c|c|c|c|}
\hline \multicolumn{2}{|c|}{$\begin{array}{l}\text { Different EAF-Slag and } \\
\text { TMWM mixtures }\end{array}$} & $\begin{array}{c}\text { EAF- } \\
\text { S01TM09 }\end{array}$ & $\begin{array}{c}\text { EAF- } \\
\text { S02TM08 }\end{array}$ & $\begin{array}{c}\text { EAF- } \\
\text { S03TM07 }\end{array}$ & $\begin{array}{c}\text { EAF- } \\
\text { S04TM06 }\end{array}$ & $\begin{array}{c}\text { EAF- } \\
\text { S05TM05 }\end{array}$ \\
\hline \multicolumn{2}{|c|}{ Porosity (\%) } & 46.51 & 28.37 & 44.09 & 26.37 & 20.38 \\
\hline \multicolumn{2}{|c|}{$\begin{array}{l}\text { Average pore diameter } \\
(\mathrm{nm})\end{array}$} & 118 & 108 & 112 & 114 & 86 \\
\hline \multicolumn{2}{|c|}{$\begin{array}{l}\text { Most probable diameter } \\
(\mu \mathrm{m})\end{array}$} & 2.5 & 2.18 & 2.53 & 2.52 & 2.19 \\
\hline \multirow{5}{*}{$\begin{array}{c}\text { Pore } \\
\text { size } \\
\text { distrib } \\
\text { ution/ } \\
\%\end{array}$} & $<20 \mathrm{~nm}$ & 5.95 & 6.39 & 6.16 & 6.21 & 8.77 \\
\hline & $20-50 \mathrm{~nm}$ & 1.85 & 1.84 & 2.05 & 1.81 & 1.91 \\
\hline & $50-200 \mathrm{~nm}$ & 4.89 & 4.68 & 4.14 & 3.55 & 4.45 \\
\hline & $200-800 \mathrm{~nm}$ & 21.45 & 21.45 & 20 & 19.15 & 21.25 \\
\hline & $>800 \mathrm{~nm}$ & 65.63 & 65.64 & 67.65 & 69.28 & 63.62 \\
\hline \multicolumn{2}{|c|}{ Total (\%) } & 100 & 100 & 100 & 100 & 100 \\
\hline
\end{tabular}

\section{Conclusions:}

From the results of compressive strengths and MIP tests conducted during this study, the following conclusions can be drawn:

$>$ The compressive strength of the AABs increase with the increasing in the amount of the EAFSlag, also the compressive strength developed by the time of cure.

$>$ The increasing of the $\mathrm{SiO}_{2} / \mathrm{Al}_{2} \mathrm{O}_{3}$ molar ratio in mixtures, influence positively in the mechanical properties of the EAF-S-TMWM-based alkaliactivated binders.

$>$ the porosities and the average pore diameter of the EAF-S-TMWM-based alkali-activated binders got degree of reduction when the EAFSlag ratio increases, and the most probable pore size significantly decreased resulting in a denser structure binder.

$>$ The porosity and the average pore diameter of the EAF-S-TMWM-AABs got degree of reduction when the dosage of EAF-Slag increases, and the most probable pore size significantly decreased resulting in a denser structure binders.

$>$ The increase in compressive strength is likely caused by the increased presence of the $\mathrm{CaO}$ due to a pozzolanic reaction causing the formation of $\mathrm{Ca}(\mathrm{OH})_{2}$ and $\mathrm{C}-\mathrm{S}-\mathrm{H}$ phases by hydration reaction of $\mathrm{CaO}$ and silica, in addition to the alkaline activation.

$>$ The increase in EAF-Slag vt.\% resulted a lower total porosity and medium values of threshold pore width for the EAF-S-TMWM-based AABs.

$>$ The paste cured for 90 days with the dosage of 50 vt.\% EAF-Slag and 50 vt.\% TMWM, has the lowest porosity and the finest pore size 
distribution, which explains the high compressive strength.

\section{Acknowledgements}

This research was partially supported by European Commission under Horizon 2020, Marie Skłodowska-Curie Actions, Research and Innovation Staff Exchange (RISE), by REMINE - "Reuse of Mining Waste into Innovative Geopolymeric-based Structural Panels, Precast, Ready Mixes and Insitu Applications". Project no 645696 (https://reminemsca.wordpress.com). Coordinator: Beira Interior University (PT) (participants: Brunel University (UK), Silesian University (PL) Bologna University (IT), Granada University (SP), Strathclyde University (UK), Alsitek Ltd (UK). Sofalca, Lda (PT), Beira Serra (PT), Alfran (SP)), $01 / 01 / 2015 \sim 31 / 12 / 2018$, project value $€ 567,000$ (EC contribution).

\section{References}

[1] F. Yonar, E. Çokgör Ubay, H. A. Dikbaş, B. Demir, and M. Ergün, "Environmental effects and possible highway applications of electric arc furnace slag in Turkey," Proc. World Congr. New Technol., no. 228, p. 228-1:10, 2015.

[2] I. Z. Yildirim and M. Prezzi, "Chemical, mineralogical, and morphological properties of steel slag," Adv. Civ. Eng., vol. 2011, 2011.

[3] EUROSLAG, EUROFER, and Waste Framework Directive, "Position Paper on the Status of Ferrous Slag," 2012.

[4] J. . Provis and J. S. J. Van Deventer, Geopolymers - Structure, processing, properties and industrial applications. Woodhed Publishing Limited and CRC Press LLC, 2009.

[5] N. Sedira, J. Castro-Gomes, G. Kastiukas, X. Zhou, and A. Vargas, "A review on mineral waste for chemical-activated binders: mineralogical and chemical characteristics," Min. Sci., vol. 24, pp. 29-58, 2017.

[6] M. M. Khater, "Influence of electric arc furnace slag on characterisation of the produced geopolymer composites," vol. 67, no. 3, p. 2015 , 2015.

[7] H. M. Khater, "Impact of electric arc furnace slag on geopolymer composites exposed to sulphate solution," vol. 2, pp. 12-26, 2017.

[8] Eurostat, "Waste statistics Main statistical findings -Total waste generation." p. 3, 2016.

[9] J. P. Castro-Gomes, A. P. Silva, R. P. Cano, J. Durán Suarez, and A. Albuquerque, "Potential for reuse of tungsten mining waste-rock in technical-artistic value added products," $J$. Clean. Prod., vol. 25, pp. 34-41, 2012.

[10] B. Wilson and F. Brian Pyatt, "Bio-availability of tungsten in the vicinity of an abandoned mine in the English Lake District and some potential health implications," Sci. Total Environ., vol. 370, pp. 401-408, 2006.

[11] T. Kraus, P. Schramel, K. H. Schaller, P. Zöbelein, A. Weber, and J. Angerer, "Exposure assessment in the hard metal manufacturing industry with special regard to tungsten and its compounds," Occup. Environ. Med., pp. 631634, 2001.

[12] F. Pacheco-Torgal, J. Castro-Gomes, and S. Jalali, "Tungsten mine waste geopolymeric binder: Preliminary hydration products investigations," Constr. Build. Mater., vol. 23, pp. 200-209, Jan. 2009.

[13] G. Kastiukas, X. Zhou, and J. Castro-Gomes, "Development and optimisation of phase change material-impregnated lightweight aggregates for geopolymer composites made from aluminosilicate rich mud and milled glass powder," Constr. Build. Mater., vol. 110, pp. 201-210, 2016.

[14] M. Criado, W. Aperador, and I. Sobrados, "Microstructural and mechanical properties of alkali activated Colombian raw materials," Materials (Basel)., vol. 9, no. 3, 2016.

[15] A. Buchwald, D. Tatarin, and R. Stephan, "Reaction progress of alkaline-activated metakaolin-ground granulated blast furnace slag blends," J. Mater. Sci., pp. 5609-5617, 2009.

[16] G. Ya-min, F. Yong-hao, Y. Duo, G. Yong-fan, and Z. Chen-hui, "Properties and microstructure of alkali-activated slag cement cured at belowAnd about-normal temperature," Constr. Build. Mater., vol. 79, pp. 1-8, 2015.

[17] H. Y. Moon, H. S. Kim, and D. S. Choi, "Relationship between average pore diameter and chloride diffusivity in various concretes," Constr. Build. Mater., vol. 20, no. 9, pp. 725732, 2006.

[18] R. A. Cook and K. C. Hover, "Mercury porosimetry of hardened cement pastes," Cem. Concr. Res., vol. 29, no. 6, pp. 933-943, 1999.

[19] D. N. Winslow and S. Diamond, "A Mercury Porosimetry Study of the Evolution of Porosity in Portland Cement," ASTM J. Mater., vol. 5, no. 3, pp. 564-585, 1969.

[20] E. J. Garboczi, "Permeability, diffusivity, and microstructural parameters: a critical review," Cem. Concr. Res., vol. 20, pp. 591-601, 1990. 